\title{
STRATEGI KEPALA SEKOLAH PEREMPUAN DALAM MENINGKATKAN MUTU PENDIDIKAN
}

\author{
${ }^{1}$ Yeni Wulandari, ${ }^{2}$ Eva Dwi Sartika, \& ${ }^{3}$ Perawati \\ ${ }^{1,3}$ SD Negeri 62 Palembang, ${ }^{2}$ SMP Utama Bakti Palembang \\ e-mail: ${ }^{1}$ yeni.wulandari2306@ gmail.com ${ }^{2}$ evads0010@ gmail.com ${ }^{3} 1704 @$ gmail.com
}

\begin{abstract}
This study aimed at describing the leadership strategy of women principal. This researchwas done in SD Negeri Kota Palembang 116. The approach used in this research was a case study. Results of the study in improving the quality of education in SD Negeri 116 Palembang include a good personal approach with all stakeholders of the school; planning the school with the greatest extent possible, analyze the challenges, barriers and opportunities in the future; establish good cooperation with all educators, empowering educational effort through cooperation, provide an opportunity to improve educators' practices, and encourage the involvement of the educators on supporting the programs of the school. The results implied the teachers to maximize the existingfacilities and infrastructure to maximize the learning process, and the school has had a strong culture.
\end{abstract}

Keywords: Women Principal; Leadership Strategy; Educational Quality

\section{PENDAHULUAN}

Artikel ini dilatarbelakangi oleh semakin banyaknya jumlah pemimpin wanita yang di sektor publik khususnya pada lembaga pendidikan, mengingat peran sentral kepala sekolah khususnya dalam menjalankan roda kepemimpinananya di lembaga pendidikan. Kepala sekolah sebagai kunci pendorong bagi perkembangan dan kemajuan sekolah serta bertanggung jawab untuk meningkatkan akuntabilitas keberhasilan siswa dan programnya (Purwanti, Murniati dan Yusrizal, 2014). Kemudian Kartono (2002) mengemukakan bahwa keberhasilan organisasi dalam mencapai tujuan yang ingin diraih bergantung kepada kepemimpinannya, yaitu apakah pemimpin tersebut mampu menggerakkan semua sumber daya manusia, sarana, dana, dan waktu secara efektif dan efisien serta terpadu dalam proses manajemen.

Dengan demikian, dapat dikemukakan bahwa kepemimpinan kepala sekolah merupakan salah satu faktor yang dapat mendorong sekolah untuk dapat mewujudkan visi, misi, tujuan, dan sasaran sekolahnya melalui program-program yang dilaksanakan dengan perencanaan yang matang. Oleh karena itu, kepala sekolah dituntut mempunyai kemampuan manajemen dan kepemimpinan yang memadai agar mampu meningkatkan mutu sekolah. Sebagaimana yang dikemukakan oleh Triwiyanto (2013) bahwa di samping diperlukan kemampuan manajemen dan kepemimpinan, komponen pengendalian manajemen Sumber Daya Manusia (SDM) pendidikan atau sering disebut dengan 
manajemen pendidik dan tenaga kependidikan sangat dibutuhkan. Manajemen pendidik menurut Kristiawan dkk (2017) adalah aktivitas yang harus dilakukan mulai dari pendidik masuk ke dalam organisasi pendidikan sampai akhirnya berhenti melalui proses perencanaan SDM, perekrutan, seleksi, penempatan, pemberian kompensasi, penghargaan, pendidikan dan latihan/ pengembangan dan pemberhentian.

Saat ini, kesetaraan gender sangat diprioritaskan oleh Negara ini dalam upaya untuk memaksimalkan sumberdaya manusia Indonesia.Tak terkecuali dalam institusi pendidikan, banyak ditemui lembaga pendidikan yang dipimpin oleh perempuan. Akan tetapi, perempuan sebagai pemimpin tidak jarang menghadapi banyak hambatan yang berasal dari berbagai aspek salahsatunya adalah espektasi masyarakat terhadap kepemimpinan tersebut.masih banyaknya pandangan masyarakat bahwa laki-laki lebih potensial menjadi pemimpin, hingga anggapan bahwa fisik wanita dianggap tidak mampu melaksanakan tugastugas berat. Peryataan tersebut ada benarnya, bila kita lihat beberapa hal yanag menjadi kodrat perempuan kemudian dapat menjadi hambatan baginya dalam menjalankan tugas sebagai pemimpin.

Tan (1991) menguraikan beberapa hambatan yang muncul dari kepemimpinan perempuan antaralain adalah: (1) hambatan fisik, seperti mengandung, melahirkan, dan menyusui. Keharusan ini dinilai mengurangi keleluasaan mereka untuk aktif terusmenerus dalam berbagai bidang kehidupan, (2) hambatan teologis bahwa untuk waktu yang lama perempuan dipandang sebagai makhluk yang dicipta untuk lelaki, temasuk mendampingi mereka, menghiburnya, dan mengurus keperluannya, (3), hambatan sosial budaya terutama dalam bentuk stereotipikal. Pandangan ini melihat perempuan sebagai makhluk pasif, lemah, perasa, tergantung, dan menerima keadaan. Sebaliknya, lelaki dinilai sebagai makhluk yang aktif, kuat, cerdas, mandiri, dan sebagainya, (4), hambatan sikap pandang yang antara lain dimunculkan oleh pandangan dikotomis antara tugas perempuan dan laki-laki. perempuan dinilai sebagai makhluk rumah, sedangkan laki-laki dilihat sebagai makhluk luar rumah, (5) hambatan historis. Kurangnya nama perempuan dalam sejarah di masa lalu bisa dipakai membenarkan ketidakmampuan perempuan untuk berkiprah seperti halnya laki-laki.

Menurut Coleman (2003), sebelum tahun 1990an, teori tentang kepemimpinan dan manajemen masih mengacu terhadap pria, penelitian mendalam tentang perempuan sebagai pemimpin sekolah masih minim dilakukan. De Witt(2010) 
mengungkapkan fakta bahwa kepemimpinan dalam pendidikan di seluruh dunia diduduki oleh pria dalam waktu yang lama, secara teoritis kerangka kerja untuk kepemimpinan dalam manajemen pendidikan masih berdasarkan padaperilaku pria.

Wanita adalah minoritas dalam manajemen di bidang pendidikan khususnya di negara berkembang yang pembangunannya sudah cukup maju (Celikten, 2011) KemudianSergiovanni, (1987) menyimpulkan bahwa perempuan cenderung menggunakan perilaku yang bersifat demokratis dalam performasinya sebagai kepala sekolah dan pelaksanaan tugas administratifnya sangat efektif. Rimmer \& Davis, (1986) mengemukakan bahwa dalam realitas sosial perempuan selalu melakukan hubungan dengan lebih hati-hati dan kooperatif.

Akan tetapi, apabila kita lihat pada saat ini, kepemimpinan kepala sekolah perempuan dinilai memberikan hasil yang nyata kearah perbaikan mutu pendidikan. Banyak pencapaian-pencapaian yang telah diraih oleh kepala sekolah yang berjenis kelamin perempuan. Penelitian yang dilakukan oleh Gross dan Task (1987).menggunakanbahwa bahwa penampilan perempuan sebagai kepala sekolah tampak lebih baik dibandingkan dengan laki-laki, moral guru lebih ditekankan pada penguasaan keterampilan teknik dan tanggung jawab mereka terhadap organisasi sekolah, dan kepala sekolah banyak menggunakan kontrol supervisi.

Kiprah wanita sebagai pemimpin juga semakin tampak di bidang pendidikan. Wanita-wanitayang menduduki posisi sebagai pemimpin. Wanita yang menduduki jabatan sebagai pemimpin dalam perguruan tinggi di dunia antara lain: Charlotte Borst(Rektor Perguruan Tinggi Idaho), Gwendolyn Elizabeth Byod (Rektor Perguruan Tinggi Alabama), dan Diane Campbell(Asisten Dekan Perguruan Tinggi Mercer County Community). Tiga wanita tersebut berada dalam jajaran teratas 25 wanita yang sukses di perguruan tinggi (West, 2015).Kemudian Usaidhelm (2015), menyebutkan contoh wanita-wanita yang sukses menduduki jabatan sebagairektor di Indonesia antara lain: Dwia Aries Tina Pulubuhu (Universitas Hass anudin) danDwikorita Karnawati (Universitas Gadjah Mada). Rachim (2015) menyatakan bahwa jumlah pekerja wanita mengalami kenaikan, akan tetapi peningkatan jumlah ini tidak tercermin dalam kesetaraan jumlah perempuan yang menduduki jabatan-jabatan kepemimpinan.

Penjelasan di atas menunjukkan bahwa kepala sekolah perempuan memiliki potensi dan kemampuan yang setara bahkan lebih dibandingkan kepemimpinan laki laki dalam meningkatkan mutu pendidikan.Salah 
satunya adalah kepala sekolah SD Negeri 116 Kota Palembang. Sekolah tersebut merupakan salah satu sekolah yang dipimpin oleh kepala sekolah perempuan. SD Negeri 116 Kota Palembang adalah salah satu sekolah dasar yang memiliki pencapaian yang baik, baik dari prestasi belajar siswa maupun sekolah. Dengan pertimbangan ini, maka penelitian ini dilaksanakan di SD Negeri 116 Kota Palembang.

\section{STRATEGI KEPEMIMPINAN KEPALA SEKOLAH}

Secara garis besar, ruang lingkup tugas kepala sekolah dapat diklasifikasikan ke dalam dua aspek pokok, yaitu pekerjaan di bidang administrasi sekolah dan pekerjaan yang berkenaan dengan pembinaan profesional kependidikan. Menurut persepsi banyak guru, keberhasilan kepemimpinan kepala sekolah terutama dilandasi oleh kemampuannya dalam memimpin. Kunci bagi kelancaran kerja kepala sekolah terletak pada stabilitas dan emosi, sertarasa percaya diri.Hal ini merupakan landasan psikologis untuk memperlakukan stafnya secara adil, memberikan keteladanan dalam bersikap, bertingkah laku dan melaksanakan tugas (Fitrah, 2017).

\section{Menurut Suprapto (2014) large} population is the most important for the progress and setbacks of a nation depends on human factors. The problems of politic, economic, social can also be completed by human resources. However, to solve the problems and deal with the high civilization competition become more advanced, Indonesia needs revitalization and strengthening strong character of human resources. One aspect that can be done to prepare for the strong human character is through education (Kristiawan, 2015). Menurut Suyatno (2010) Education is the only key that can achieve strong human resources (Kristiawan, 2015).

Menurut Suprapto (2014) Pendidikan karakter tidak sekadar mengajarkan mana yang benar dan mana yang salah, tetapi juga menanamkan kebiasaan (habituation) tentang hal mana yang baik. Dengan begitu, peserta didik menjadi paham (kognitif) tentang mana yang baik dan salah, mampu merasakan (afektif) nilai yang baik (loving the good/moral feeling), dan perilaku yang baik (moral action), dan biasa melakukan (psikomotor) (Kristiawan, 2016).

Untuk mencapai peningkatan mutu sesuai dengan apa yang diharapkan, sangat dibutuhkan sosok kepala sekolah yang memiliki karakter, tangguh, komunikator, dan memiliki keahlian dalam mengorgainisasi setiap personal yang dipimpinnya. Slamet (2000) menjelaskan karakteristik kepala sekolah tangguh, yaitu: (1) memiliki wawasan jauh kedepan dan tahu tindakan apa yang harus dilakukan serta 
paham benar tentangcara yang akan ditempuh, (2) memiliki kemampuan mengkoordinasikan dan menyerasikan seluruh sumberdaya terbatasyang ada, (3) memiliki kemampuan mengambil keputusan, memobilisasi sumber daya yang ada toleransi terhadap perbedaan, dan (4) memiliki kemampuan memerangi musuhmusuh kepala sekolah, yaitu ketidak pedulian, kecurigaan, tidak membuat keputusan, mediokrasi, imitasi, arogansi, pemborosan, kaku, dan bermuka dua dalam bersikap dan bertindak.

Mutu sekolah terdiri dari setiap komponen yang saling mendukung satu dengan lainnya (suatu sistem). Dengan demikian mutu sistem tergantung pada mutu komponen yang membentuk sistem, serta proses yang berlangsung hingga membuahkan hasil. Dalam pelaksanaan manajemen peningkatan mutu, kepala sekolah harus senantiasa memahami sekolah sebagai suatu sistem organisasi (Suwardi, 2014).

Oleh karena itu, dibutuhkan beberapa strategi dalam upaya meningkatkan mutu pendidikan yang dilakukan oleh kepala sekolah. Menurut Fauzuddin (2011) ada beberapa strategi yang dilakukan kepala sekolah dalam mencapai sekolah efektif antara lain: (1) optimalisasi proses pembelajaran, memberdayakan potensi siswa, dan (3) menjalin kerja sama dengan berbagai pihak untuk mendukung prestasi siswa. Sedangkan faktor-faktor pendukung dalam meningkatkan prestasi sekolah adalah: (1) input siswa yang unggul dan terseleksi, (2) memperoleh dukungan dari komponen sekolah, (3) jalinan kerjasama dan kemitraan dengan orang tua, masyarakat, pemerintah, pihak swasta, dan lembaga pendidikan internasional.

\section{KEPEMIMPINAN PEREMPUAN}

Keutamaan wanita adalah kemampuan untuk memelihara hubungan. Wanita tertarik untuk membantu orang lain berkembang dan mengungkapkan diri serta menolong mereka memperoleh kepuasan. Sifat memelihara berasal dari peran biologis wanita. Wanita memiliki kemampuan alami untuk mencipta, memelihara, dan mendorong pertumbuhan semua itu dilakukan demi dan bersama orang lain (Wolfman, 1989) Faktor-faktor kunci untuk mencapai keberhasilan wanita menurut Steel dan Thornton (1994) antara lain: (1) Kemampuan untuk mengenali, menciptakan, dan menangkap kesempatan, (2) Menyadari kebutuhan orang di tempat kerja, (3) Perlunya dukungan di segala tingkat, (4) Determinasi untuk berhasil, (4) kualifikasi, (5) memiliki kepekaan akan ekspresif.

Menurut Sandon (2006), kemampuan wanita dalam memimpin terbentuk dan 
terpengaruh dari karakter individual, dari dalam dan dari luar lingkungan. Hal tersebut misalnya terlihat pada saat mereka memilih pilihan tertentu dalam bertindakyang berbeda dengan orang lain, mempertahankan sikap, seringkali memutuskan sesuatu dalam jangka waktu yang lama, danpada saat menghadapi berbagai kesulitan dan masalah. Hasan dan Othman (2013) menyatakan bahwa pemimpin wanita yang berbakat dan percaya diri memiliki beberapa karakteristik yang pada umumnya berbeda dari laki-laki. Dahlvig dan Longman mengidentifikasi tiga sudut pandang penting yang membawa wanita pada kepemimpinan, yaitu: memperhatikan secara lebih luas, kepuasan hari demi hari, struktur sosial organisasi. Menganjurkan organisasi lebih sehat dan produktif ketika pandangan pria dan wanita diterima dan disukai.

Selanjutnya, Hasan dan Othman (2013), dalam temuan penelitiannya mengemukakan empat pernyataan spesifik tentang kualitas kepemimpinan wanita: (1) kemimpin perempuan lebih persuasif dari laki-laki, (2) ketika merasakan penolakan, pemimpin perempuan belajar dari kesulitan yang mereka alami, (3) kemimpin wanita menunjukkan sebuah keterlibatan secara keseluruhan, membangun tim kerja gaya kepemimpinan termasuk pemecahan masalah dan pengambilan keputusan, dan (4) kemimpin perempuan lebih mungkin untuk mengabaikan aturan dan mengambil risiko.

Menurut Zubaidi, Farad Rajwan et al. (2011), faktor -faktor yang membuat wanita dapat menduduki posisi sebagai pemimpin yaitu: (1) faktor sosial budaya, (2) faktor pribadi, (3) pelatihan kemepimpinan wanita, (4) perilaku atasan pria, (5) diskriminasi, (6) mentoring,

pemberdayaan

\section{METODE PENELITIAN}

Penelitian ini bertujuan untuk mendeskripsikan tentang strategi kepemimpinan kepala sekolah perempuan dalam menjalankan kepemimpinananya. Penelitian ini dilaksanakan di SD Negeri 116 Kota Palembang. Rancangan penelitian ini adalah kualitatif, studi kasus. Penelitian kualitatif adalah one of research procedure that produces descriptive data in form of words, writing, and behavior of the people being observed (Kristiawan dan Elnanda, 2017). Kemudian Case Study menurut Yuliani dan Kristiawan (2017) sebagai suatu metode untuk memahami individu yang dilakukan secara integratif dan komprehensif agar diperoleh pemahaman yang mendalam tentang individu tersebut beserta masalah yang dihadapinya. Pengumpulan data dilakukan oleh peneliti sendiri sebagai instrumen utama yang dilakukan pada latar alamiah. Teknik 
pengumpulan dalam penelitian ini adalah observasi, wawancara, dan dokumentasi. Data yang dikumpulkan terkait dengan Strategi yang dilakukan kepala sekolah perempuan dalam mencapai sekolah efektif, dan Faktor-faktor pendukung dalam meningkatkan prestasi sekolah di SD Negeri 116 Kota Palembang. Sumber data dalam penelitian ini adalah kepala sekolah, wakil kepala sekolah, guru-guru, dan orang tua siswa. Data yang dikumpulkan dianalisis secara deskriptif melalui alur: reduksi data, penyajian data, dan penarikan kesimpulan.

\section{HASIL PENELITIAN DAN PEMBAHASAN}

Dalam upaya meingkatkan mutu pendidikan, kepala sekolah SD Negeri 116 Kota Palembang memiliki strategi dalam menjalankan fungsi-fungsinya sebagai edukator, manajer, administrator, supervisor, leader, inovator, dan motivator. Adapun strategi tersebut antaralain adalah dengan melakukan pendekatan personal. Kepala sekolah melakukan pendekatan personal yang baik dengan seluruh stakeholder sekolah. Dengan pendekatan yang baik tersebut, kepala sekolah dapat dengan mudah membimbing guru, tenaga kependidikan, siswa di sekolah untuk menjalankan tugas dan tanggung jawabnya masing-masing dengan strategi ini, kepala sekolah dapat menjalin hubungan yang baik dengan seluruh stakeholder di sekolah tersebut, tanpa mengurangi wibawanya sebagai seorang kepala sekolah di SD Negeri 116 Kota Palembang. hal ini sesuai dengan pendapat fitrah (2017) bahwa kepala sekolah sebagai edukator, kepala sekolah bertugas untuk membimbing guru, tenaga kependidikan, siswa, mengikuti perkembangan iptek, dan memberi teladan yang baik.kemudian Vivi (2013) bahwa untuk menciptakan iklim sekolah yang kondusif diperlukan kerjasama atau hubungan yang harmonis antara seluruh warga sekolah dan tidak hanya menjadi tanggung jawab kepala sekolah semata.Oleh karena itu upaya yang dapat dilakukan kepala sekolah dalam meningkatkan kinerjanya sebagai edukator, khususnya dalam peningkatan kinerja tenaga kependidikan dan prestasi belajar peserta didik adalah mengikutsertakan guru-guru dalam pendidikan lanjutandengan cara mendorong para guru untuk memulai kreatif dan berprestasi.

Kemudian, stragtegi kepala sekolah SD Negeri 16 Kota Palembang dalam upaya meningkatkan mutu pendidikan di SD Negeri 116 Kota Palembang adalah dengan menyusun perencanaan sekolah dengan semaksimal mungkin, menganalisa tantangan, hambatan serta peluang kedepan yang akan dihadapi oleh SD Negeri 116 Kota Palembang dalam upaya meningkatkan mutu pendidikannya. Dalam menyusun 
perencanaan sekolah, kepala sekolah SD Negeri 116 Kota Palembang selalu melibatkan seluruh stakeholder sekolah dan menjalinkoordinasi dalam melaksanakan kegiatan yang telah ditetapkan sebagai program sekolah. Selain itu, kepala sekolah SD Negeri 116 Kota Palembang berupaya untuk selalu meningkatkan fungsi pengawasannya, melakukan evaluasi terhadap kegiatan, mengadakan rapat yang baik terjadwal maupun yang tidak terjadwal, dan menjalankan seluruh tugas tanggungjawabnya bersama-sama dengan seluruh stakeholder sekolah. Sebagaimana yang dikemukakan oleh Sabirin (2012) bahwa kepala sekolah sebagai manajer, mempunyai fungsi:menyusun perencanaan, mengkoordinasikan kegiatan, melakukan pengawasan, melakukan evaluasi terhadap kegiatan, mengadakan rapat, mengambil keputusan, mengatur proses pembelajaran, mengatur administrasi, dan mengatur tata usaha, siswa, ketenagaan, sarana, dan prasarana, keuangan.

Kemudian, strategi kepala sekolah dalam meningkatkan mutu tenaga pendidik di SD Negeri 116 Kota Palembang, adalah dengan selalu menjalin kerjasama yang baik dengan seluruh pendidik dan tenaga pendidik di SD Negeri 116 Kota Palembang. Kepala sekolah, menyadari bahwa mutu pendidikan tidak akan tercapai apabila tidak didukung oleh kerja sama yang kuat antara seluruh pihak sekolah. Khususnya dalam meningkatkan mutu pembelajaran, kepala sekolah SD Negeri 116 Kota Palembang sangat menekankan kepada setiap tenaga pendidik agar selalu menjaga integritasnya sebagai seorang pendidik.Oleh karena itu, kepala sekolah selalu melibatkan tenaga pendidik di SD Negeri 116 Kota Palembang dalam kegiatan yang telah menjadi program sekolah. Hal ini, dimaksudkan agar, tenaga pendidik di SD Negeri 116 Kota Palembang merasa memiliki tugas dan tanggungjawab terhadap kesuksesan program sekolah tersebut. hal ini sesuai dengan pendapat yang dikemukakan oleh Sunarto (2011) bahwa untuk melakukan peran dan fungsinya sebagai manajer, kepala sekolah harus memiliki strategi yang tepat untuk: (1) memberdayakan tenaga kependidikan melalui kerjasama, (2) memberi kesempatan kepada para tenaga kependidikan untuk meningkatkan profesinya, dan mendorong keterlibatan seluruh tenaga kependidikan yang menunjang program sekolah. Karena jika merujuk pada pandangan manajemen modern, kerjasama merupakan hal yang amat mendasar dalam sebuah organisasi.

Dengan demikian, kepala sekolah SD Negeri 116 Kota Palembang, berharap bahwa dengan pengelolaan yang telah dilaksanakan dengan baik, serta dengan mengikutsertakan seluruh stakeholder 
sekolah dalam meningkatkan mutu pendidikan secara bersama-sama bahu membahu, maka sekolah dapat dengan cepat menjawab dan merespon tantangan tantangan baru kedepannya.oleh karena itu, kepala sekolah SD Negeri 116 Kota Palembang, sangat menyadari bahwa perlunya penguasaan dan wawasan yang luas untuk dapat membaca setiap perubahan yang akan menjadi tantangan kedepan bagi upaya peningkatan mutu pendidikan. Oelh karena itu, kepalas ekolah selalu menekankan kepada seluruh tenaga pendidik agar selalu menjadikan karya ilmiah sebagai problem solving apabila mengalami kendala dalam menjalankan tugas dan tanggungjawabnya. Kepala sekolah sadar betul bahwa dengan selalu berupaya menambah wawasannya, tenaga pendlidik akan dapat menjalankan tugas dan tanngungjawabnya dengan efektif dan efisien. Hal ini sesuai dengan pendapat yang dikemuakan oleh Sunarto (2011) bahwa kepala sekolah sebagai kategori administrasi pendidikan perlu melengkapi wawasan kepemimpinan pendidikan dengan pengetahuan dan sikap yang antisipatif terhadap perubahan yang terjadi dalam kehidupan masyarakat, termasuk kebijakan pendidikan. Sebagai seorang administrator, kepala sekolah harus memiliki kemampuan untuk memperbaiki dan mengembangkan semua fasilitas sekolah. Secara spesifik, kepala sekolah juga dituntut untuk mengelola kurikulum, mengelola administrasi sarana dan prasarana, mengelola administrasi kearsipan, dan mengelola administrasi keuangan.

Hasil yang didapatkan dari strategi yang dijalankan oleh kepala sekolah SD Negeri 116 Kota Palembang dapat dilihat dari meningkatnya mutu pendidikan di sekolah tersebut.Walaupun SD Negeri 116 Kota Palembang memiliki sarana dan prasarana yang cukup memadari, namun sekolah berupaya untuk dapat memaksimalkan setiaap potensi yang ada di sekolah tersebut.selain itu, pendidik dan tenaga pendidik di SD Negeri 116 Kota Palembang dapat menjalin kerjasama yang baik, memberikan contoh yang baik dan selalu menjaga etikanya. Hal ini menandakan bahwa sudah terbentuk budaya sekolah yang membangun di SD Negeri 116 Kota Palembang.Dengan demikian, dapat dikemukakan bahwa jenis kelamin tidak mempengaruhi efektivitas kepemimpinan kepala sekolah dalam upaya meningkatkaan mutu pendidikan.

\section{KESIMPULAN}

Dalam upaya meningkatkan mutu pendidikan, kepala sekolah SD Negeri 116 Kota Palembang memiliki strategi antara lain (1) melakukan pendekatan personal yang baik dengan seluruh stakeholder 
sekolah, (2) melakukan perencanaan sekolah dengan semaksimal mungkin, menganalisa tantangan, hambatan serta peluang kedepan yang akan dihadapi sekolah, (3) menjalin kerjasama yang baik dengan seluruh pendidik dan tenaga pendidik dengan memberdayakan tenaga kependidikan melalui kerjasama, memberi kesempatan kepada para tenaga kependidikan untuk meningkatkan profesinya, dan mendorong keterlibatan seluruh tenaga kependidikan yang menunjang program sekolah. Dengan penerapan startegi tersebut, hasil yang telah di dapat oleh pihak sekolah adalah: (1) guru telah mampu memaksimalkan sarana dan prasarana yang ada untuk memaksimalkan proses pembelajaran dan pendidikan yang ada di sekolah, (2) sekolah telah memiliki budaya yang kuat yaitu budayasekolah yang membangun.

\section{DAFTAR PUSTAKA}

Celikten, M. (2011). The instructional leadership tasks of high school assistan principals. Emerald Insight : Journal of Educational Administration, Vol. 39 Iss $1 \mathrm{pp}$.

Coleman, JS. (2003). Foundation of Social Theory. Harvard University Press, Cambriedge and. London.

Dahlvig, Jolyn., Longman, Karen A. (2014). Contributors To Women's Leadership Development In Christian Higher Education: A Model and Emerging Theory. Journal of Research on
Christian Education, Vol. 23, pp, 528.1

Dewitt, K.A. (2010). Sleep Disorders Breathing and Pregnancy. http://www.ncbi.nlm.nih.gov/pmc/artic les.

Fauzuddin.(2011). Kepemimpinan Transformasional Kepala Sekolah. Disertasi. Program Pascasarjana universitas Negeri Malang. Tidak dipublikasikan.

Fitrah, M. (2017). Peran kepala sekolah dalam meningkatkan mutu pendidikan. Jurnal Penjamin Mutu : 31-42

Kartono, K. (2002). Pemimpin dan Kepemimpinan: Apakah pemimpin abnormal itu?. Jakarta:CV. Rajawali.

Kristiawan, M. (2015). A Model of Educational Character in High School Al-Istiqamah Simpang Empat, West Pasaman, West Sumatera. Research Journal of Education, 1(2), 15-20.

Kristiawan, M. (2016). Telaah Revolusi Mental Dan Pendidikan Karakter Dalam Pembentukkan Sumber Daya Manusia Indonesia Yang Pandai dan Berakhlak Mulia. Ta'dib, 18(1), 13-25.

Kristiawan, M., Safitri, D., \& Lestari, R. (2017). Manajemen Pendidikan. Yogyakarta: Deepublish

Kristiawan, M., \& Elnanda, D. (2017). The Implementation of Authentic Assessment in Cultural History of Islam Subject. Al-Ta lim Journal, 24(3).

Hasan, A. Othman, A. (2013). When It Comes To Leadership, Does Gender Matter? Arabian Journal

Purwanti, K., Murniati, A.R. dan Yusrizal. 
(2014). Kepemimpinan Kepala Sekolah Dalam Meningkatkan Kompetensi Guru Pada SMP Negeri 2 Simeulue Timur. JurnalIlmiah Didaktika XIV(2), 390-400.

Rimmer, C \& Davis, B. (1986). Women Principal in Education Departemen, High Schoolin Victoria. The Journal of Education Administration. XXIII (2), 153-187.

Tan, M. G (ed). (1991). Perempuan IndonesiaPemimpin Masa Depan?. Jakarta: PustakaSinarHarapan.

Triwiyanto, T. (2013). Pemetaan Mutu Manajemen Berbasis Sekolah Melalui Audit Manajemen Pendidikan. Jurnal Manajemen Pendidikan.24 (2): 125135.

Sergiovanni, TJ. (1987). The Principleship, AReflective Practice Perspective. London: Allyn and Bacon, Inc.

Steel, Maggie., Zita Tohrnton. (1994), Wanita Mampu Meraih Karier Gemilang, Jakarta: Binarupa Aksara.

Sabirin (2012). Perencanaan Kepala Sekolah Tentang Pembelajaran. Jurnal Tabularasa PPS UNIMED, 9(1), 111128.

Sunarto (2011). Pengaruh Gaya Kepemimpinan Kepala Sekolah, Manajemen Berbasis Sekolah dan Iklim Organisasi Terhadap Kepuasan Kerja dan Kinerja Guru SMP di Wilayah Sub Rayon 04 Kabupaten Demak. Jurnal AnalisisManajemen,5(1), 17-29.

Suwardi, S. (2014). Kepemimpinan Kepala Sekolah Dalam Pengembangan Lembaga Pendidikan Islam Kreatif SD Muhammadiyah Kota Madiun. Jurnal Manajemen Pendidikan, 9(2), 186-
195.

Vivi, Rusmawati. (2013). Peran Kepemimpinan Kepala Sekolah Dalam Upaya Meningkatkan Disiplin Kerja Guru Pada SDN 018 Balikpapan. EJournal Administrasi Negara.1(2), 395-409.

West, Cassandra. (2016) Women's History Month Top 25 Women In Higher Education \& Beyond, Diverse Education. pp.12-22.

Wolfman, Brunetta. R. (1989)Peran Kaum Wanita. Yogyakarta: Kanisius.

Yuliani, T., \& Kristiawan, M. (2017). Peran Kepemimpinan Kepala Sekolah dalam Membina Kompetensi Sosial (Pelayanan Prima) Tenaga Administrasi Sekolah. JMKSP (Jurnal Manajemen, Kepemimpinan, dan Supervisi Pendidikan), 1(2).

Zubaidi, Farad Rajwan et al. (2011) An Overview on Women's Leadership Issues In Jordan, Journal of Politics and Law, Vol.4, No. 2 